\title{
Climbing up the ladder: male reproductive behaviour changes with age in a long-lived fish
}

\author{
Marek Šmejkal ${ }^{1}$ (D) Daniel Bartoň ${ }^{1} \cdot$ Marek Brabec $^{2} \cdot$ Zuzana Sajdlová $^{1} \cdot$ Allan T. Souza ${ }^{1} \cdot$ Karlos R. Moraes $^{1}$. \\ Kateřina Soukalová ${ }^{1} \cdot$ Petr Blabolil ${ }^{1} \cdot$ Lukáš Vejrík $^{1} \cdot$ Jan Kubečka ${ }^{1}$
}

Received: 2 September 2020 /Revised: 16 December 2020 / Accepted: 28 December 2020 / Published online: 12 January 2021

(C) The Author(s) 2021

\begin{abstract}
High reproductive performance is the key attribute of male fitness, especially due to the high reproductive skew among the males of most animal species. Males of long-lived iteroparous species have opportunities to improve upon their previous reproductive attempts with increasing age. We collected individual-specific reproductive behaviour and age data on a cyprinid fish, the asp (Leuciscus aspius), from 2015 to 2019. We tested whether males changed their performance over time using a unique dataset where individual performance was recorded yearly with passive telemetry. Individual fish behaviour was tracked from one to five reproductive seasons at least a year after the tagging. Fish were scored by measures of quality (first arrival time, number of visits and time spent in the reproductive grounds, and encountered proportion of males to all adult fish). In general, fish improved in the first three metrics with age, suggesting a shift towards behaviours likely to enhance reproductive success as individuals aged. A larger size at tagging was predictive of earlier fish arrival on the spawning ground in subsequent years. Our study therefore demonstrates the importance of age as a factor when considering the potential reproductive success of long-lived fish species.
\end{abstract}

\section{Significance statement}

High reproductive performance is the key attribute of male fitness. Males of long-lived species reproducing multiple times in their life have opportunities to improve upon their previous reproductive performance with increasing age. In this 5-year study, we tracked a large cyprinid fish with telemetry systems during their reproduction. We investigated the age-related behavioural changes in males and demonstrated the improvement of male reproductive timing and length of stay with potential repercussions for male's reproductive output. We emphasize the importance of old and experienced individuals among the fish population, which are often targeted and selectively removed from the human-managed waters.

Keywords Telemetry $\cdot$ Reproductive behaviour $\cdot$ Long-term monitoring $\cdot$ Fish ecology $\cdot$ Resource-holding potential

\section{Introduction}

Animals acquire experience during their lifetime, which provides them with an important baseline for their decisions and behavioural changes through ontogeny (Chivers and Smith

Communicated by J. Lindström

Marek Šmejkal

marek.smejkal@hbu.cas.cz

1 Institute of Hydrobiology, Biology Centre of the Czech Academy of Sciences, České Budějovice, Czech Republic

2 Institute of Computer Science, Czech Academy of Sciences, Prague, Czech Republic
1994; Hollen and Radford 2009; Roth and Krochmal 2015). The onset of reproductive ability and choice of successful reproductive strategy are crucial decisions affecting animal fitness. The possibility of reproducing multiple times in a lifetime, known as iteroparity, provides individuals with the chance to improve on their reproductive readiness (i.e. ability to gain early matings), as well as the potential to learn more efficient mating strategies (i.e. ability to achieve more matings within a given reproductive season; Becker et al. 2008; Arnaud et al. 2013). Hence, low initial reproductive success in the first reproductive season may be compensated for by relatively higher reproductive success later in life (Bowen et al. 2006; Limmer and Becker 2010; Arnaud et al. 2013).

In polygynandrous mating systems with a balanced sex ratio and female-limited reproductive rate, males are under 
stronger selective pressure than females due to higher variability of reproductive success (Clutton-Brock and Vincent 1991; Hasselquist 1998; Kruuk et al. 1999; Elgee et al. 2012). This presumably drives selection for males that can learn based on experience and adjust their performance accordingly for the subsequent reproductive season, with the goal of maximizing individual reproductive success. To maximize their reproductive output, males of many bird and fish species often arrive earlier than females on average (a sex-biased arrival timing termed protandry; reviewed in Morbey and Ydenberg 2001) and leave the reproductive grounds later than females (Morbey 2000; Canal et al. 2012; Briedis et al. 2019). The advantage provided for males in territory-defending species is early acquisition of high quality territories, and the earlyarriving males consequently have better access to females (rank advantage hypothesis, Morbey and Ydenberg 2001; Pärt 2001). In non-territorial species, this phenomenon can be simply driven by the higher number of females encountered by early males compared to late-arriving males (mate opportunity hypothesis, Morbey 2003; Kokko et al. 2006).

In terms of individual reproductive success, males that are able to arrive early generally attain higher fitness compared to late-arriving individuals (Møller et al. 2009; Gienapp and Bregnballe 2012; Arnaud et al. 2013). In male territorial contests, the arrival time and thus the potential residency status acquisition is an important factor favouring the odds of winning the dispute over the territory, such as in male-male contests of cichlid fish Oreochromis mossambicus (Turner 1994). Prior residence effect favouring resident of a territory was found to be an important determinant of contest outcome in fish, amphibians, reptiles, birds and mammals (Koivula et al. 1993; Haley 1994; Turner 1994; Olsson and Shine 2000; Yang et al. 2020). The earlier arrival may additionally allow an individual to evaluate potential competitors ahead of the main reproductive season and assess their competitive abilities (Johnsson and Åkerman 1998; Oliveira et al. 1998).

Aside from the arrival time, body size is an important factor that shapes contest outcomes among males on the reproductive grounds, with large body size providing a substantial advantage for winning the male-male contest (Turner 1994; Arnott and Elwood 2009). As a consequence, large male size provides opportunity to achieve high rank status and is generally a good predictor of male reproductive success (Quinn and Foote 1994; Järvi 2010). Large male body size may also be preferred by females, providing males better access to receptive females (Dechaume-Moncharmont et al. 2011).

In many breeding systems, reproductive groups can be formed on a daily basis, and individual males decide how much time to allocate to reproductive effort not just across the season as a whole but also on a given day (Trail and Adams 1989; Šmejkal et al. 2017). In reproductive systems where the environmental conditions at the reproductive grounds are harsh and require high levels of energy expenditure, animals may make temporary migrations to staging areas, returning to the main breeding grounds once their energy reserves are restored (Šmejkal et al. 2017). The number of migrations performed and overall time allocation to reproduction likely reflect individual condition and competing abilities. Finally, in mating system in which both sexes arrive to and depart from reproductive ground multiple times and with various timing tactics, the operational sex ratio (number of available males and females) is constantly changing, and individuals experience various operational sex ratios based on their time choices (Ancona et al. 2017; Clutton-Brock 2017).

Behavioural studies investigating the effect of age (and therefore mating experience) on reproductive performance have tended to focus on long-lived birds and mammalsgroups that are the most studied in behavioural sciences and allow relatively easy tracking of their actual reproductive output (Bowen et al. 2006; Limmer and Becker 2009, 2010; Robinson et al. 2012; Rosenthal et al. 2017). However, among fish, surprisingly little is known about the relationship between reproductive performance and age in wild populations (but see Tibblin et al. 2016).

In this study, we analyzed the effects of age and male body size (standard length) at the tagging on reproductive performance in a long-lived cyprinid fish-the asp (Leuciscus aspius). This fish has a simple mating system where adults gather on an energy-intensive fluvial spawning ground in the early spring and males compete for females in a month-long reproductive period. During reproduction, males are distributed at approximately equal distances within the river and chase away competitors if the spacing between them becomes too small, which results in frequent shifts in their positions (Šmejkal et al. 2017). Each male performance in a given year was evaluated by telemetry tracking (first arrival time on the spawning ground, number of visits to the spawning site from staging ground per season, total time spent on the spawning ground and the proportion of males to total fish encountered) in relation to age and the initial size. We hypothesized that males would improve in performance parameters with increasing age; specifically, older males would (i) arrive earlier, (ii) perform more spawning visits, (iii) spend more time in the spawning grounds, and (iv) time their visits to encounter lower competition for females.

\section{Materials and methods}

\section{Study site}

The study was performed in the tributary of Želivka Reservoir, which is located at $49^{\circ} 34^{\prime} 42^{\prime \prime} \mathrm{N}$ and $15^{\circ} 15^{\prime} 14^{\prime \prime}$ $\mathrm{E}$ in the Czech Republic. The impoundment created by the Želivka dam generated a $39.1 \mathrm{~km}$ long artificial water body, with an area of 1602 ha at a maximum water level of $381.7 \mathrm{~m}$ 
above sea level. A weir located on the river just above the reservoir blocks further upstream migration and restricts spawning of the rheophilous asp to a well-defined spawning ground less than $100 \mathrm{~m}$ long at a site that is $22 \mathrm{~m}$ wide on average (Fig. 1; Šmejkal et al. 2017).

\section{Studied species}

The asp is a European fish species in the family Cyprinidae, subfamily Leuciscinae, that inhabits lakes and rivers, but only the latter habitat is suitable for asp reproduction (Kottelat and Freyhof 2007). Fish living in a lacustrine environment, such as in our study system, migrate in the early spring to a fluvial spawning ground, where they spawn at low water temperatures ranging between 5 and $14{ }^{\circ} \mathrm{C}$ (Krrížek and Vostradovský 2002; Šmejkal et al. 2018). Males compete for ready-to-spawn females, and during their encounters, males vigorously chase females for several metres. Spawning events are terminated by the release of batches of eggs by females near the water surface and the simultaneous fertilization of eggs by one or multiple males (Šmejkal et al. 2018). Asp have no parental care; therefore, males aim to maximize their fitness by maximizing the number of encounters with females by having higher time and activity allocations and earlier arrival times compared to those of the females (Morbey and Ydenberg 2001). Both sexes arrive at and depart from the spawning grounds multiple times per reproductive season (Fig. 1), migrating downstream 1 to $3 \mathrm{~km}$ to the staging grounds (Šmejkal et al. 2017). The asp is a capital breeder that obtains energy stores for breeding in the previous growing season and does not feed during the reproductive period (Stephens et al. 2009; Al-Saleh et al. 2012). The size of adult asp ranges usually from 40 to $80 \mathrm{~cm}$ in standard length (SL). They mature usually between fourth and seventh year of life and may live up to approximately 15 years. The reproductive period is the only time when asp sex can be visually determined with certainty using morphological and physiological traits (see below).

\section{Fish capture, tagging and migration recording}

Spawners were captured at the staging grounds using an electrofishing boat (electrofisher EL 65 II GL DC, Hans Grassel, Schönau am Königsee, Germany; 13 kW, 300/600 V) in the spawning seasons from 2014 to 2018 . The fish were anaesthetized with MS-222, and their standard length (in mm), sex and weight (in g) were recorded. The males were distinguished by milt release, breeding tubercles and slender bodies, while the females had no tubercles, robust bodies and released

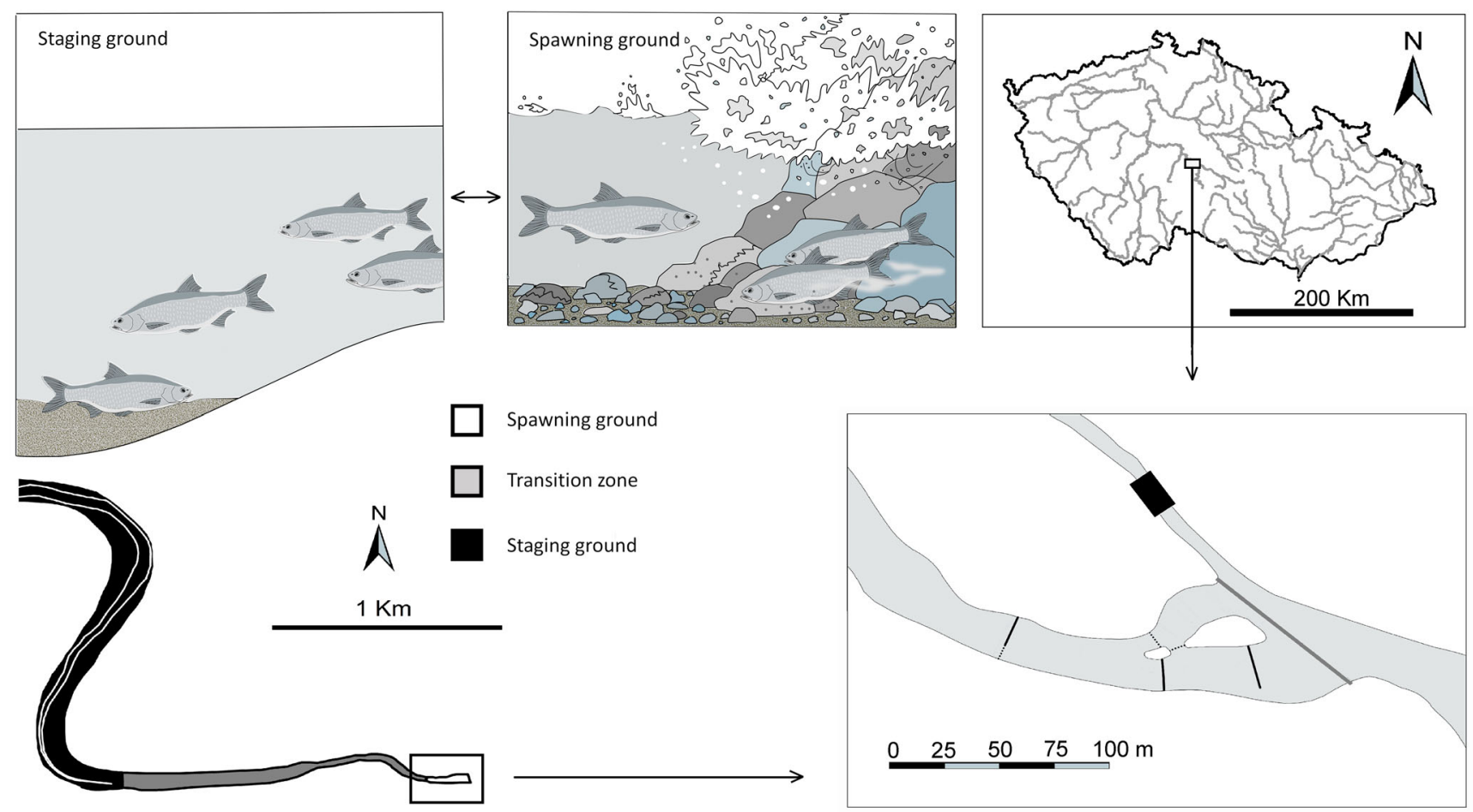

Fig. 1 Schematic representation of the visits to the spawning grounds (left panel), position of studied location in the Czech Republic (top right panel) and detail of spawning ground with the antenna deployment setup (bottom right panel). Spawning visits: after a certain amount of time spent on the spawning ground, the asp departs downstream to the standing water of the reservoir; the staging grounds span from one to three kilometres downstream. White line depicts the occurrence of depth $3 \mathrm{~m}$ or lower. Antenna deployment setup: placement of antenna systems is indicated by solid black lines. Nets guiding asps into passing through the antennas are indicated by dotted lines. The migration further upstream (right side direction) is restricted by a weir (solid grey line) and reproduction typically occurs in the most fluvial part between the weir and the second antenna. We used QGIS software for the graphical visualization (QGIS Development Team 2016) 
eggs if they were ready to spawn. During tagging, a passive integrated transponder tag (PIT tag, Oregon RFID, Oregon, USA; half-duplex; length: $32 \mathrm{~mm}$; diameter: $3.65 \mathrm{~mm}$; weight: $0.8 \mathrm{~g}$; ISO 11784/11785 compatible) was inserted into the body cavity after removing 3-4 scales and performing a 4 $5 \mathrm{~mm}$ vertical incision $3 \mathrm{~cm}$ posterior to the pelvic fin. Removed scales were stored for subsequent age estimation. No sutures were used to close the incision (Skov et al. 2005; Hulthén et al. 2014). The tag loss via scar wound is minimal (less than 1\%), but females expel their tags with approximately $11 \%$ probability (Šmejkal et al. 2019). The tagged individuals were released immediately after recovery from anaesthesia. The counts of tagged males in 2014 to 2018 were sequentially $221,209,360,283$ and 162, for a total of 1235 individuals (mean SL $471 \mathrm{~mm} \pm 33 \mathrm{~mm}$ standard deviation (SD)). Furthermore, 138, 182, 254, 301 and 202 females, respectively, were tagged in these years, totalling 1077 fish (mean SL $494 \mathrm{~mm} \pm 46 \mathrm{~mm} \mathrm{SD}$ ). The tagged sample size represented a substantial part of the mature asp population in the studied reservoir; the population size of the adults based on the mark-recapture estimate was 2000 individuals on average and had an approximately balanced sex ratio (Šmejkal et al. 2017).

To minimize observer bias, blinded methods were use when all behavioural data were recorded and analyzed. The tagged individuals were monitored on the spawning grounds by passive telemetry using Oregon RFID antenna systems (LF HDX RFID readers). The electromagnetic field created within the antenna loop energizes the PIT tag in a tagged individual that passes by the antenna and then emits an individual fish code that is recorded and stored along with the date and time in the antenna reader. Two antennas in 2015 and three antennas from 2016 to 2019 with synchronized time settings were installed on the spawning grounds approximately $50 \mathrm{~m}$ apart (Fig. 1). The asps were guided by barriers to swim through the 10-m wide antenna electromagnetic field (Šmejkal et al. 2017). The system scanning frequency was set to 10 energizing and reading cycles* ${ }^{-1}$, and the systems were tested daily to ensure that they were scanning their entire detection range. Antenna monitoring in a given year began prior to the beginning of asp spawning (no or few asp detected in first monitoring days) and continued until the majority of the asp had disappeared from the spawning grounds (Supplementary Table 1).

\section{Data analysis}

\section{Telemetry data treatment and processing}

Fish that were tagged and detected by the passive telemetry systems in the same year were excluded from the analysis due to a possible influence of the tagging procedure on their behaviour and due to likely incomplete information acquisition (e.g. missed first arrival time). Hence, only the fish that arrived at least a year after tagging were analyzed. Each fish recorded by any of the antennas was defined as a potential spawner and counted as present. Due to possible PIT tag collisions and missed detections caused by multiple tagged fish in the antenna field (Burnett et al. 2013), we defined fish departure as the absence of detection of a given individual for more than $2 \mathrm{~h}$ after the last detection. The minimum presence time at the spawning grounds was defined as a 10-min visit. Following this definition, single detection of individuals with more than a 2-h gap from another detection was extended to a 10-min spawning visit, which assumed that fish could participate to some extent in reproduction with other fish at the site.

\section{Age estimation}

Scales collected during the tagging were cleaned and placed in the microfiche reader (Indus 4601-01, World Micrographics \& Imaging, Columbus, USA) with magnification set at 24 and number of fully developed annuli was assessed (Howland et al. 2004). The scale with the best readability from each individual was chosen for age estimation and this scale was subjected to single reading by a single observer. Regenerated scales were omitted from age determination.

\section{Statistical analysis}

The first arrival time, number of visits, total time spent on the spawning grounds and encountered proportion of males to overall number of asp were computed for the data analysis. First arrival time was defined as first detection of an individual in a season and the individual protandry degree was defined as a difference between the individual arrival time and the average female arrival time. The total time spent on the spawning grounds and number of visits were counted following the 2-h departure definition rule described above. Data were processed using packages tidyverse, dplyr, data.table and lubridate within R software version 4.0.1 (Dowle 2016; Spinu et al. 2017; Wickham et al. 2019a, b; R Development Core Team 2020).

Since there were many instances where males encountered zero females within a given visit to the spawning ground, we were unable to calculate encounter rates based on sex-ratio. We therefore used just the proportion of males encountered as our dependent variable. The final encountered proportion of males $\left(\mathrm{p}_{\mathrm{m}}\right)$ for each individual was computed as the proportion of males $\left(p_{i}\right.$, the number of males divided by the total number of asps) during all visits of an individual per year weighted by time allocations in visits $\left(\mathrm{t}_{\mathrm{i}}\right)$ using the formula:

$p_{m}=\frac{\sum_{i=1}^{n}\left(p_{i} t_{i}\right)}{\sum_{i=1}^{n} t_{i}}$ 
In order to evaluate whether data standardization is needed before analyses, we tested the potential differences in levels of investigated behavioural traits (first arrival time, number of visits, total time spent, and encountered proportion of males) across five monitored years (2015-2019) using a generalized additive model (GAM) with a year as explanatory variable. Fish ID was set as random effect. Furthermore, we evaluated skewness of the raw data distribution using D'Agostino skewness test (null hypothesis of symmetry (zero skewness) against positive skew alternative) for all four behavioural traits (see result section for test outputs). Based on the test results, we used rank transformation for two reasons: (i) fish performance difference among monitored years (and beyond our capacity to explain via available covariate values), and (ii) nonnormality of original data. Ranking within a given year was used as a form of year-specific normalization.

The individual performance was compared to those of other fish that were reproducing in the given season. Fish were ranked by their performance relative to the order of best male performance in each year separately (omitting newly tagged individuals), i.e. the best rank (the lowest) meant that the individual had the first arrival in the given year, highest number of visits, highest amount of time spent, and the lowest encountered proportion of males. Each male had therefore four separate scores in a given year, if it was detected by passive telemetry systems. For visual representation, ranks were standardized on a 0 to 100 scale, with the lowest value indicating the best performance in a given year. Since we did not obtain good quality scales for all individuals, a subset of males (633) of which scales with good age readability were obtained during tagging and that arrived at least one reproductive season following the tagging procedure was chosen for the analysis of the effects of age and size at the tagging on reproductive performance.

A flexible (semiparametric) GAM (Hastie and Tibshirani 1990; Wood 2017) was used for each rank parameter (ranks in first arrival time, number of visits, total time spent, and encountered proportion of males) to qualitatively assess how the various ranks as dependent variables were influenced by the explanatory variables of interest (age and length at tagging). Fish ID was set as random effect. For the analysis, ranks were rescaled to a limited range of 0 to 1 intervals, we use a beta distribution (Johnson et al. 1995) for the response (employing logistic link, (McCullagh and Nelder 1989)). Furthermore, since the functional shape of the relationship between a given response variable and explanatory was not known a priori, we use penalized spline components (Eilers and Marx 1996) to account for potential nonlinearity between the ranks and length at tagging. The $p$ values for the tests of the non-penalized effects (age and length) are based on Wald tests using the Bayesian covariance matrix for the estimated coefficients (Wood 2017). For the penalized term, the $p$ values are also computed via procedure exploiting frequentist properties of Bayesian covariance matrix of estimates (Wood 2013). To ensure that the spline model is flexible enough to capture potential nonlinearity in the response with respect to various terms, we started with a rich enough basis (of dimension 9). Then we checked whether the basis is rich enough via k-index and a simulation-based test for the k-index (Wood 2017).

Spearman's correlation matrix was used to estimate and test the interdependences among the four ranks defined above. For significant trends among ranks, a simple linear regression was visualized to demonstrate the interdependence of ranks. The statistical analyses were performed using $\mathrm{R}$ software version 4.0.1 and package mgcv (Wood 2001; R Development Core Team 2020) and data were visualized using ggplot2 (Wickham 2016).

\section{Data availability}

The datasets analyzed during the current study are available from the corresponding author upon request.

\section{Results}

From 2015 to 2019, the counts of males that returned for at least 1 year after tagging were 100, 167, 318, 390 and 456, respectively. The average first arrival time of the females, which was needed for protandry computation, was based on the 51, 98, 228, 327 and 438 previously tagged females that arrived in reproductive seasons 2015 to 2019, respectively. The males arrived on average 5.2 days \pm 3.4 SD before the females, visited the spawning grounds 18.9 times $\pm 10.1 \mathrm{SD}$, spent $29.5 \mathrm{~h} \pm 29.6 \mathrm{SD}$ on the spawning grounds and encountered a proportion of males of $0.78 \pm 0.09 \mathrm{SD}$. The average visit of the spawning ground performed by male lasted $1 \mathrm{~h}$ $41 \mathrm{~min} \pm 3 \mathrm{~h} 55 \mathrm{~min}$ SD and interval between first and last male visit was on average 10 days $\pm 5 \mathrm{SD}$. Arrival time (AT), number of visits (NV), time spent (TS) and proportion of males (PM) were significantly differed among years (AT $\mathrm{F}(4)=21.8, p<0.001 ; \mathrm{NV}-\mathrm{F}(4)=68.0, p<0.001 ; \mathrm{TS}-$ $\mathrm{F}(4)=33.2, p<0.001$ and $\mathrm{PM}-\mathrm{F}(4)=159.3, p<0.001)$. Data were characterized by right hand skewness in first three variables $(\mathrm{AT}=1.06, Z=13.7, p<0.001 ; \mathrm{NV}=0.76, \mathrm{Z}=10.5, p$ $<0.001 ; \mathrm{TS}=2.45, Z=23.2, p<0.001 ; \mathrm{PM}=-0.27, \mathrm{Z}=$ $-4.1, p=1$; Fig. 2).

Due to frequent occurrence of regenerated scales in the scale samples, total number of males in 2015-2019 with estimated age that arrived on the spawning ground was 58, 149, 291, 359 and 419 with average male age of $6.5,6.6,6.9,7.5$ 
Fig. 2 Scaled density plots of the absolute scores of the four measured behavioural variables for all males in 2015-2019
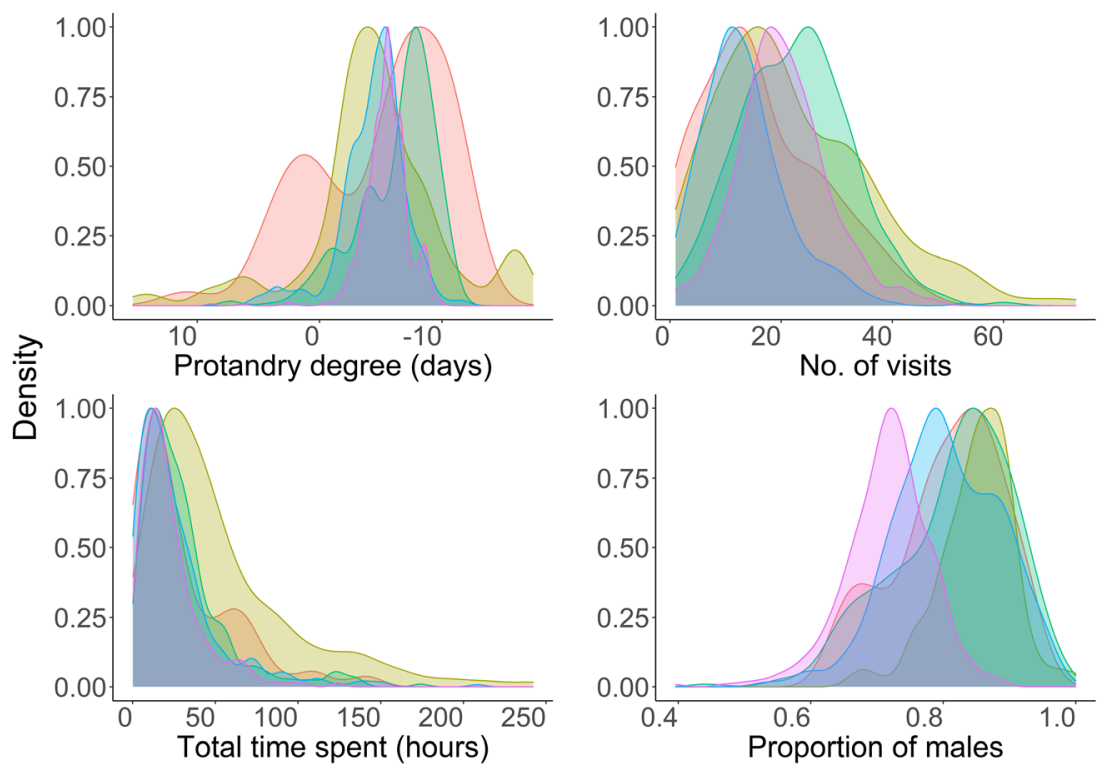

$2015 \square 2016 \square 2017 \square 2018 \square 2019$ and 8.2, respectively. The number of reproductive seasons recorded for males with a known age varied from one to five with 262, 176, 134, 45 and 16 occurrences, respectively.

Males arrived earlier in the season, visited the spawning grounds more times and spent more time on the spawning grounds with increasing age (Fig. 3, Supplementary Fig. 1, Table 1). There was no apparent change with age in the proportion of males encountered (Table 1). The GAM models using the ranks arrival time (abbreviation for model: ArM),

Table 1 GAM models with the dependent variables first arrival time (ArM), number of visits (ViM), total time spent (TiM), and encountered proportion of males (PrM), respectively, and the independent variables tagging length and age. Effect of ID was set as a random effect in the models. The models explained 53.5 (ArM), 32.9 (ViM), 31.6 (TiM), and $24.8 \%$ (PrM) of the deviance using the dependent variables first arrival time, number of visits, total time spent, and encountered proportion of males, respectively

\begin{tabular}{llrrr}
\hline GAM model & & \multicolumn{1}{c}{ edf } & \multicolumn{1}{c}{$\chi^{2}$} & \multicolumn{1}{c}{$p$} \\
\hline ArM & ID & 263.80 & 535.32 & $<0.001$ \\
& age & 1.00 & 11.07 & $<0.001$ \\
& length & 1.00 & 6.92 & $<0.001$ \\
ViM & ID & 153.04 & 228.49 & $<0.001$ \\
& age & 1.81 & 2.27 & $<0.001$ \\
& length & 1.86 & 1.38 & 0.559 \\
TiM & ID & 147.49 & 217.17 & $<0.001$ \\
& age & 1.21 & 11.13 & 0.001 \\
& length & 1.50 & 0.93 & 0.446 \\
PrM & ID & 119.50 & 167.28 & $<0.001$ \\
& age & 1.00 & 0.43 & 0.511 \\
& length & 1.00 & 0.24 & 0.627 \\
& & & & \\
\hline
\end{tabular}

number of visit (ViM), time spent (TiM) and proportion of males (PrM) had adjusted $\mathrm{R}^{2}$ of 0.313 (ArM), 0.155 (VrM), 0.151 (TiM) and 0.111 (PrM) and explained 53.5 (ArM), 32.9 (ViM), 31.6 (TiM), and 24.8\% (PrM) of the deviance, respectively. Fish ID had significant influence on the fish rank in all models. Length at tagging had a significant effect on arrival time, with larger males arriving on average earlier, but no effect on the three remaining traits (Table 1).

Individual ranks across the four variables were significantly correlated. First arrival time was positively correlated with the number of visits and total time spent on the spawning ground, while early arrival also significantly indicated a relatively higher competition for females on the spawning ground. The number of visits was highly correlated with the total time spent (Table 2, Fig. 4).

In general, the highest competition for females occurred at the beginning of the spawning season (proportion of males larger than $80 \%$ in all years) due to protandry. The late season competition varied among years with high competition in 2015 and 2016 (proportion of males approximately 80\%), fluctuating between 50 and $70 \%$ in 2017 and femaledominated trend in 2018 and 2019 (proportion of males 2040\%; Fig. 5).

\section{Discussion}

Data obtained from telemetry tracking of male asp over five annual spawning seasons showed that males improved their performance with respect to three out of four reproductive traits as they aged: earlier arrival to spawning grounds, longer time spent and number of visits to the spawning ground. These 
Fig. 3 The violin plots and boxplots of changing patterns of relative performance in relation to age in four measured parameters: first arrival time, number of visits, total time spent and proportion of males in the total number of adult fish. The boxes represent the boundaries of the upper and lower quartiles, the thick lines represent medians and the whiskers upper and lower adjacent value. The lowest value indicates the best performance (i.e. 1 - the first arrival in the spawning season)
Arrival time

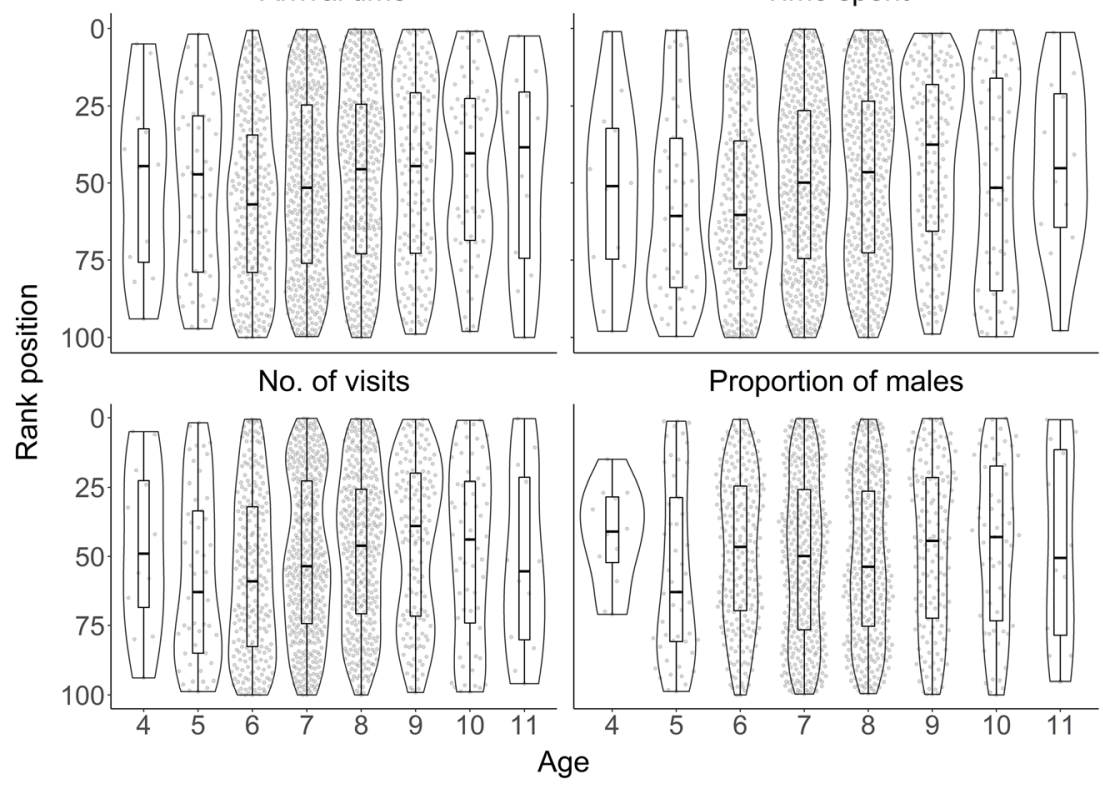

improvements suggest an individual's potential to improve yearly reproductive success over time. While the three abovementioned parameters improved on average with increasing age, the fourth parameter-the proportion of males to total fish encountered - did not seem to change with increasing age. While this could be interpreted as a failure of the strategy of the aged males, it could also suggest higher competitive ability of the individuals that attempt to acquire females early in the spawning season, when the competition is the highest, as is the typical quality of mates (Morbey and Ydenberg 2001; Morbey et al. 2012; Hau et al. 2017). Moreover, when males stayed on the spawning grounds longer and generally arrived earlier in the season, it was impossible to find a female-dominated time window, while late in the reproductive season, such conditions were not unusual in spawning seasons 2018 and 2019.

The female-dominated end of the spawning season also occurs in other spawning systems, such as in salmon spawning migration (Ueda et al. 2007). This may have several reasons: the majority of males may become exhausted or sperm-depleted before the arrival of the last females (Jonsson et al. 1991; Smith et al. 2009). Alternatively, the late laying date may be evaluated not optimal by males, since asp times their reproduction in very early spring, which gives offspring early-hatching advantage in comparison with later spawning cyprinids competing for common food sources (Mark et al. 1987; Hladík and Kubečka 2003). Finally, the female size may be larger in the beginning of spawning season such as in other reproductive systems (Cuadrado and Loman 1999; Slotte et al. 2000), favouring early male allocation of spawning effort. The proportion of males on the spawning ground did not have the same trend across years but maintained relatively high levels in 2015 and 2016. Reproduction was slowed down by pronounced cold periods in these years. This may have affected the male performance, but longer time series would be needed to investigate the annual variation on the sex ratio development on the spawning ground.

We chose four parameters to measure individual quality over the years: first arrival time, number of visits, total time spent and individually encountered proportion of males. These parameters seemed to be indicative of individual quality for several reasons. The ranking of the first arrival time reflected the individual degree of protandry, which showed how individual fish coped with harsh conditions just after

Table 2 Spearman's correlation matrix of the four ranks computed for the variables first arrival time, number of visits, total time spent, and encountered proportion of males. Correlation coefficient is located in lower triangular and corresponding p-values in upper triangular of a correlation matrix

\begin{tabular}{lcccc}
\hline & Arrival & No. of visits & Total time & Proportion of males \\
\hline Arrival & - & $<0.001$ & $<0.001$ & $<0.001$ \\
No. of visits & 0.31 & - & $<0.001$ & 0.728 \\
Total time & 0.15 & 0.69 & - & 0.046 \\
Proportion of males & -0.47 & 0.01 & 0.06 & - \\
\hline
\end{tabular}


Fig. 4 Simple linear regressions among the ranks of arrival time, number of visits, total time spent and proportion of males. Values are given as ranks $(0-100$ scale), with the lowest values indicating the best observed performance recorded in the season. The identity line is visualized to demonstrate a 1:1 ratio between the two rank types. The red line indicates a regression trend and the shaded area $95 \%$ confidence interval

Simple linear regression models among ranks
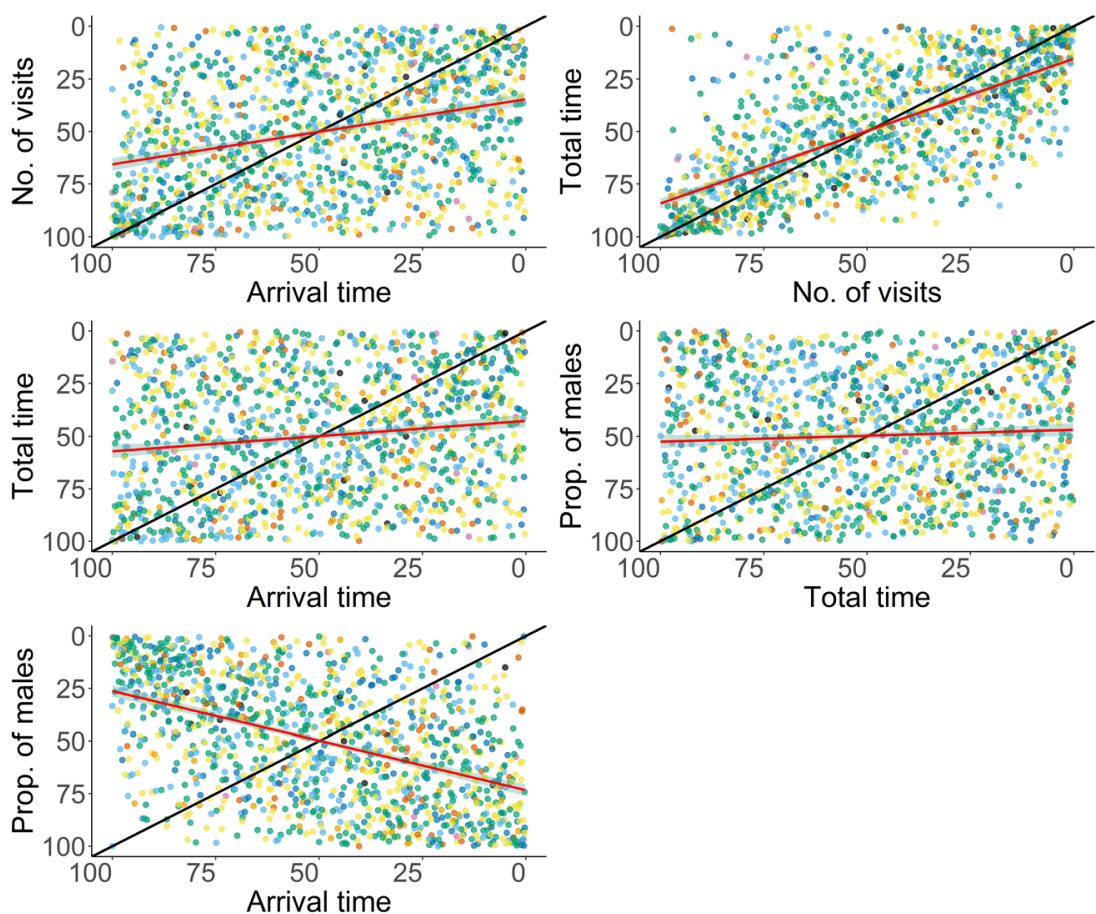

Age $: 45: 6: 8: 10$

the winter and entered the fluvial conditions of the spawning ground. The overall time allocations were accompanied by the potentially highest energy expenditures for all parameters, since asps have to stay in a water current with a speed of between 0.1 and $0.5 \mathrm{~m} . \mathrm{s}^{-1}$ for many hours (top individuals spend more than $100 \mathrm{~h}$ ) (Šmejkal et al. 2017), and this

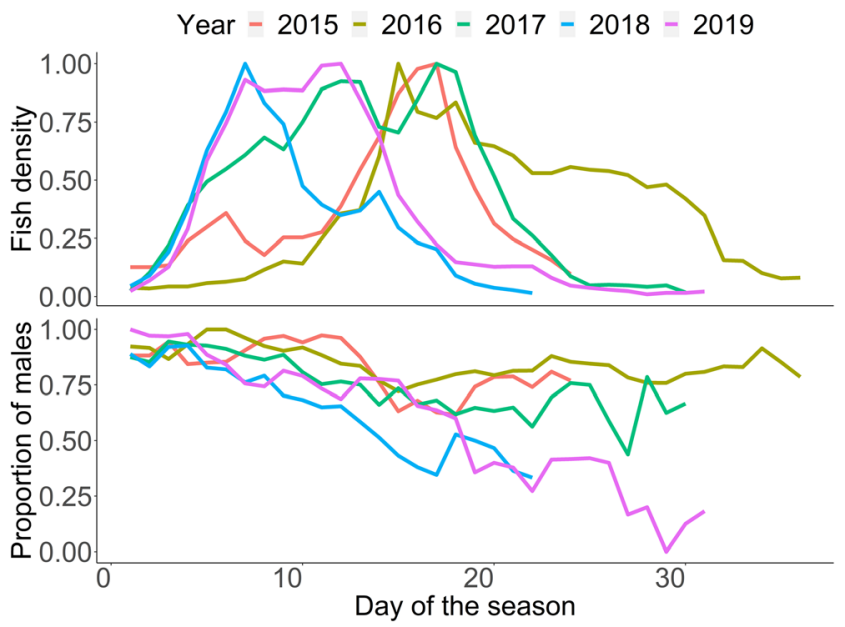

Fig. 5 Fish density (top panel) and the proportion of males (bottom panel; number of males to total number of adult asps) development on the spawning grounds during the monitored seasons. Fish density was standardized to the maximum number of fish present in the year. The first day of the season was defined as the first day with at least five tagged individuals on the spawning ground parameter indicates which one of them were the most persistent. Similar to the total time allocations, the number of visits was accompanied by energy expenditures due to the distance swam between the spawning and resting grounds.

Fish ID had significant influence in all models, suggesting important effect of individual personality upon the fish behavioural parameters (Niemelä et al. 2015; Michelangeli et al. 2016). This shows importance of including ID random effect in the models (without it, the non-negligible intra-individual correlation would lead to false perception of larger than real precision of the estimates).

We observed overall trends in the measures of male performance, but actual male performance consists of many variables. First arrival time, number of visits and total time spent are variables that generally indicate male quality in many taxa (Morbey and Ydenberg 2001). In pink salmon (Oncorhynchus gorbuscha), early arrival and long presence on the spawning ground was found a good indication of high male reproductive success (Dickerson et al. 2002, 2005). In our study, the number of eggs fertilized in the reproductive season or ideally the number of sired offspring that survive until reproductive age would be preferable variables (Kruuk et al. 1999; Thériault et al. 2011). Since asps reach adulthood in their fourth to seventh years of life, it is extremely time-demanding and costly to perform such studies. Therefore, we limited our research to the behavioural parameters computed from individual detections by the passive telemetry systems. Although observed 
patterns likely indicate an increase in male resource-holding potential (individual access to females) with age, more research is needed to verify these expectations.

In the majority of animal species, males have skewed reproductive success, where a relatively small portion of males fertilize the majority of females (Ross et al. 2020). In studies, male resource-holding potential is often assessed in studies indirectly by individual size (Arnott and Elwood 2009). Our study showed that in arrival time, size was indicative of the position of the individuals relative to the others. Size in our study was measured only at the beginning of the fish history and changed over time. Therefore, if the size was known for each year, its indicative value might be even higher. However, since we focused mainly on the behavioural changes during this period, we did not undergo extensive efforts to recapture fish and measure their length increments. While this strategy could shed some light on the effect of size on the ranking, repeated electrofishing could also substantially reduce the competitive ability of an individual and even lead to mortality (Snyder 2003), especially in physically exhausted males.

In animals with indeterminate growth, large size strongly correlates with age, and in many species, large individuals or those in better condition precede small individuals in their arrival (Rajasilta 2001; Vandeperre and Methven 2007), and the same pattern was detected in our study. Noticeable exception of this general pattern represent study on the three-spined stickleback (Gasterosteus aculeatus), where small males arrive earlier on the spawning grounds, settle territories and build nests despite high predation risk early in the season. Larger males arrive later than small males and are able to take over the territories of small males (Candolin and Voigt 2003). However, in the majority of mating systems, the owner of the territory usually has an advantage and a higher chance of winning a dispute (Turner 1994; Arnott and Elwood 2009).

The asp reproductive system that is under scrutiny is very unique since 2000 adult asps inhabiting a $39 \mathrm{~km}$ long reservoir migrate to mate in the spatially limited spawning grounds with a length of only 50-100 m (Šmejkal et al. 2017). Therefore, there is quite strong competition among males for advantageous positions in the stream. Studies relating reproductive output to ageing in other species have shown an increase in reproductive output until senescence lowers reproductive performance (Bowen et al. 2006; Rebke et al. 2010; Robinson et al. 2012). Senescence often does not influence all fitnessrelated traits equally, but some traits may be more affected by the ageing process than others, as was demonstrated in e.g. superb fairy wrens (Malurus cyaneus) or common tern (Sterna hirundo; Zhang et al. 2015; Cooper et al. 2020). Considering age-specific performance, each individual has to balance maximizing mating success in the current season and the possibility of saving energy for reproduction in the following seasons to maximize lifetime reproductive success (Fleming 1996; Scharf et al. 2013). Trends in male traits indicated a slight drop in rank of number of visits and time spent in the oldest individuals. While it seems that the ageing process did not affect all traits equally, longer time series with more numerous aged individuals are needed to test this directly.

The tendency of older and more experienced individuals to shift the arrival and activity to early in the spring may have had several advantages for future male fitness. While offspring sired early in the spring could benefit from higher food availability, (Reglero et al. 2018), predation by bleak on asp eggs, which was described recently on the studied spawning ground, predominantly targets the late spawning season (Šmejkal et al. 2018), and it could be advantageous to avoid it by early arrival. On the other hand, the higher water temperature available for late mates might ultimately provide their offspring with faster development and shorten the egg phase. Furthermore, arriving too early in the season may have negative fitness consequences for individuals due to harsher environmental conditions (Møller 1994; Olsson and Madsen 1996; Bêty et al. 2004).

Both male and female asps tend to leave spawning grounds for some time and return to spawning, a behaviour that we call a spawning visit performed on average twice a day and lasting less than $2 \mathrm{~h}$. Such behaviour may be related to the physiological state of fish. Competition and courtship can be extremely demanding and are also accompanied by exercise-induced imbalance in metabolite levels that accumulate in the fish body, and physiological recovery may take up to $12 \mathrm{~h}$ (Kieffer 2000). Therefore, the metabolite levels and their effect on a fish's actual competitive ability within the shoal may lead to a strategy of short but frequent visits to the spawning ground. However, we have to point out that the departure from and subsequent arrival on the spawning grounds is also not cost-free, since asp have to swim between three and six kilometres to get on the staging grounds and back to the reproductive ground. However, further research on the spawning visit strategy should be performed to verify whether male exhaustion is behind the observed behaviour.

Competitive outcomes among males are usually studied in the lab in relatively small-bodied and short-lived fish species (Oliveira et al. 1998; Elgee et al. 2012; Johnson et al. 2018) or in salmonids (Dickerson et al. 2002; Morbey 2003; Seamons and Quinn 2010), which usually have short life spans and do not experience as many reproductive seasons as long-lived species. The notable exception for long-lived species is represented by a study on northern pike (Esox lucius) in the Baltic region conducted by Tibblin et al. (2016), who sampled northern pike with fyke nets. Contrary to our findings, larger males arrived later than smaller males, suggesting that larger males can compensate for late arrival by high competitive ability (Tibblin et al. 2016). While in this study, the fish trapping could influence the fish behaviour, we recorded fish behaviour automatically by passive telemetry at least a year after tagging, 
trying to minimize the changes in the behaviour triggered by the methodology.

One of the hypotheses for evaluating reproductive improvement with increasing age states that differential survival of high- and low-quality individuals may disproportionally lead to observed improvements in individual reproductive performance due to higher mortality of low quality individuals (Wooller et al. 1990; Rebke et al. 2010). However, this trend seemed not to be the case in this study, since we observed on average gradual improvement of individuals instead of the disappearance of low-quality individuals. Furthermore, larger individuals tended to have higher starting first arrival rank, indicating that size was partly behind the variation in first arrival rank. Length also provides better swimming capacity fluvial environments, facilitating larger fish in good condition to remain on the spawning grounds longer than smaller individuals (Kieffer 2000; Ojanguren and Braña 2003). On the other hand, although size is correlated with age in fish, there is variation in energy allocation between reproduction and growth producing variation in body length at a given age (Mittelbach et al. 2014); hence, both size and age should be considered.

To conclude, our research showed age- and length-related trends in the reproductive performance of long-lived fish. The improvement was significant in three out of four measured variables. Males tended to arrive early, invest more time and perform more spawning visits with increasing age. The further scientific focus on reproductive performance may shed light upon the role of experienced individuals in population ecology, which may be important, especially in populations that are under human influence, where older and more experienced individuals are selectively removed (Arlinghaus et al. 2010; Ahrens et al. 2020).

Supplementary Information The online version contains supplementary material available at https://doi.org/10.1007/s00265-020-02961-7.

Acknowledgements We thank Luboš Kočvara, Tomáš Kolařík, Zdeněk Popelka, Zdeněk Prachař and Vladislav Draštík for their assistance during field work. Thank you to Vilém Děd and Marco Badici for database design and data handling. We are grateful to two anonymous reviewers for their helpful comments.

Authors' contributions MŠ, DB, PB, KM, ZS, AS, LV and JK participated in the field work. MS designed the study. KS estimated age from fish scales. AS, KM and MŠ prepared the telemetry data for the analysis. MB conducted the statistical analysis. MŠ wrote the first draft. All authors contributed substantial feedback during manuscript preparation. All authors gave final approval for publication and agree to be held accountable for the work performed therein.

Funding This research was supported by the project "The enhancement of rheophilous fish reproduction in the artificial river environment" (No. TJ02000012), by the NAZV project "Aquaculture of rheophilous fish" (No. QK1920326), by Strategy AV21 of the Czech Academy of Sciences and by VP20 - Water for life and by the long-term strategic development financing of the Institute of Computer Science (Czech Republic RVO 67985807).

\section{Compliance with ethical standards}

Conflict of interest The authors declare that they have no conflict of interest.

Ethical approval The field sampling and experimental protocols used in this study were performed in accordance with the guidelines and permission from the Experimental Animal Welfare Commission under the Ministry of Environment of the Czech Republic (ref. no. CZ 01679). Methods and ethics of the study were approved by the Experimental Animal Welfare Commission of Biology Centre of the Czech Academy of Sciences.

Informed consent Not applicable.

Open Access This article is licensed under a Creative Commons Attribution 4.0 International License, which permits use, sharing, adaptation, distribution and reproduction in any medium or format, as long as you give appropriate credit to the original author(s) and the source, provide a link to the Creative Commons licence, and indicate if changes were made. The images or other third party material in this article are included in the article's Creative Commons licence, unless indicated otherwise in a credit line to the material. If material is not included in the article's Creative Commons licence and your intended use is not permitted by statutory regulation or exceeds the permitted use, you will need to obtain permission directly from the copyright holder. To view a copy of this licence, visit http://creativecommons.org/licenses/by/4.0/.

\section{References}

Ahrens RNM, Allen MS, Walters C, Arlinghaus R (2020) Saving large fish through harvest slots outperforms the classical minimum-length limit when the aim is to achieve multiple harvest and catch-related fisheries objectives. Fish Fish 21:483-510. https://doi.org/10.1111/ faf. 12442

Al-Saleh F, Hammoud V, Hussein A, Alhazzaa R (2012) On the growth and reproductive biology of asp, Aspius vorax, population from the middle reaches of Euphrates River. Turkish J Fish Aquat Sci 12: 149-156. https://doi.org/10.4194/1303-2712-v12_1_17

Ancona S, Dénes FV, Krüger O, Székely T, Beissinger SR (2017) Estimating adult sex ratios in nature. Phil Trans R Soc B 372: 20160313

Arlinghaus R, Matsumura S, Dieckmann U (2010) The conservation and fishery benefits of protecting large pike (Esox lucius L.) by harvest regulations in recreational fishing. Biol Conserv 143:1444-1459. https://doi.org/10.1016/j.biocon.2010.03.020

Arnaud CM, Becker PH, Dobson FS, Charmantier A (2013) Canalization of phenology in common terns: genetic and phenotypic variations in spring arrival date. Behav Ecol 24:683-690

Arnott G, Elwood RW (2009) Assessment of fighting ability in animal contests. Anim Behav 77:991-1004

Becker PH, Dittmann T, Ludwigs J-D, Limmer B, Ludwig SC, Bauch C, Braasch A, Wendeln H (2008) Timing of initial arrival at the breeding site predicts age at first reproduction in a long-lived migratory bird. P Natl Acad Sci USA 105:12349-12352

Bêty J, Giroux JF, Gauthier G (2004) Individual variation in timing of migration: causes and reproductive consequences in greater snow geese (Anser caerulescens atlanticus). Behav Ecol Sociobiol 57:1-8 
Bowen WD, Iverson SJ, McMillan JI, Boness DJ (2006) Reproductive performance in grey seals: age-related improvement and senescence in a capital breeder. J Anim Ecol 75:1340-1351. https://doi.org/10. 1111/j.1365-2656.2006.01157.x

Briedis M, Bauer S, Adamík P, Alves JA, Costa JS, Emmenegger T, Gustafsson L, Koleček J, Liechti F, Meier CM, Procházka P, Hahn S (2019) A full annual perspective on sex-biased migration timing in long-distance migratory birds. Proc R Soc B 286: 20182821. https://doi.org/10.1098/rspb.2018.2821

Burnett NJ, Stamplecoskie KM, Thiem JD, Cooke SJ (2013) Comparison of detection efficiency among three sizes of half-duplex passive integrated transponders using manual tracking and fixed antenna arrays. North Am J Fish Manag 33:7-13

Canal D, Jovani R, Potti J (2012) Multiple mating opportunities boost protandry in a pied flycatcher population. Behav Ecol Sociobiol 66: $67-76$

Candolin U, Voigt H-R (2003) Size-dependent selection on arrival times in sticklebacks: why small males arrive first. Evolution 57:862-871

Chivers DP, Smith RJF (1994) Fathead minnows, Pimephales promelas, acquire predator recognition when alarm substance is associated with the sight of unfamiliar fish. Anim Behav 48:597-605

Clutton-Brock T (2017) Reproductive competition and sexual selection. Phil Trans R Soc B 372:20160310

Clutton-Brock TH, Vincent AC (1991) Sexual selection and the potential reproductive rates of males and females. Nature 351:58-60

Cooper EB, Bonnet T, Osmond HL, Cockburn A, Kruuk LBE (2020) Ageing and senescence across reproductive traits and survival in superb fairy-wrens (Malurus cyaneus). Am Nat (published online, https://doi.org/10.1086/711755)https://doi.org/10.1086/711755)

Cuadrado M, Loman J (1999) The effects of age and size on reproductive timing in female Chamaeleo chamaeleon. J Herpetol 33:6-11. https://doi.org/10.2307/1565536

Dechaume-Moncharmont FX, Cornuau JH, Keddar I, Ihle M, Motreuil S, Cézilly F (2011) Rapid assessment of female preference for male size predicts subsequent choice of spawning partner in a socially monogamous cichlid fish. CR Biol 334:906-910. https://doi.org/ 10.1016/j.crvi.2011.08.004

Dickerson BR, Brinck KW, Willson MF, Bentzen P, Quinn TP (2005) Relative importance of salmon body size and arrival time at breeding grounds to reproductive success. Ecology 86:347-352. https://doi. org/10.1890/03-625

Dickerson BR, Quinn TP, Willson MF (2002) Body size, arrival date, and reproductive success of pink salmon, Oncorhynchus gorbuscha. Ethol Ecol Evol 14:29-44. https://doi.org/10.1080/08927014. 2002.9522759

Dowle M (2016) Package 'data.table.' Cran. https://CRAN.R-project.org/ package $=$ data.table. Accessed 20 Aug 2019

Eilers PHC, Marx BD (1996) Flexible smoothing with B-splines and penalties. Stat Sci 11:89-121. https://doi.org/10.1214/ss/ 1038425655

Elgee KE, Ramnarine IW, Pitcher TE (2012) Multiple paternity, reproductive skew and correlates of male reproductive success in a wild population of the Trinidadian guppy. Ecol Freshw Fish 21:109-118. https://doi.org/10.1111/j.1600-0633.2011.00528.x

Fleming IA (1996) Reproductive strategies of Atlantic salmon: ecology and evolution. Fish Rev Fish Biol Fish 6:349-416. https://doi.org/ 10.1007/BF00164323

Gienapp P, Bregnballe T (2012) Fitness consequences of timing of migration and breeding in cormorants. PLoS One 7:e46165

Haley MP (1994) Resource-holding power asymmetries, the prior residence effect, and reproductive payoffs in male northern elephant seal fights. Behav Ecol Sociobiol 34:427-434. https://doi.org/10. 1007/BF00167334

Hasselquist D (1998) Polygyny in great reed warblers : a long-term study of factors contributing to male fitness. Ecology 79:2376-2390. https://doi.org/10.2307/176829
Hastie T, Tibshirani R (1990) Generalized additive models. Chapman Hall \& CRC, Boca Raton

Hau M, Dominoni D, Casagrande S, Buck CL, Wagner GC, Hazlerigg D, Greives T, Hut RA (2017) Timing as a sexually selected trait: the right mate at the right moment. Phil Trans R Soc B 372:20160249

Hladík M, Kubečka J (2003) Fish migration between a temperate reservoir and its main tributary. Hydrobiologia 504:251-266

Hollen LI, Radford AN (2009) The development of alarm call behaviour in mammals and birds. Anim Behav 78:791-800

Howland KL, Gendron M, Tonn WM, Tallman RF (2004) Age determination of a long-lived coregonid from the Canadian north: comparison of otoliths, fin rays and scales in inconnu (Stenodus leucichthys). Ann Zool Fenn 41:205-214. https://doi.org/10.7939/ R3DS0H

Hulthén K, Chapman BB, Nilsson PA, Hansson L-A, Skov C, Baktoft H, Brodersen J, Brönmark C (2014) Sex identification and PIT-tagging: tools and prospects for studying intersexual differences in freshwater fishes. J Fish Biol 84:503-512

Järvi T (2010) The effects of male dominance, secondary sexual characteristics and female mate choice on the mating success of male Atlantic salmon Salmo salar. Ethology 84:123-132. https://doi. org/10.1111/j.1439-0310.1990.tb00789.x

Johnson NL, Kotz S, Balakrishnan N (1995) Beta distributions. In: continuous univariate distributions, vol. 2, 2nd edn. Wiley, Hoboken, $\mathrm{NJ}$

Johnson SL, Zellhuber-Mcmillan S, Gillum J, Dunleavy J, Evans JP, Nakagawa S, Gemmell NJ (2018) Evidence that fertility trades off with early offspring fitness as males age. Proc R Soc B 285: 20172174. https://doi.org/10.1098/rspb.2017.2174

Johnsson JI, Åkerman A (1998) Watch and learn: preview of the fighting ability of opponents alters contest behaviour in rainbow trout. Anim Behav 56:771-776. https://doi.org/10.1006/anbe.1998.0824

Jonsson N, Jonsson B, Hansen LP (1991) Energetic cost of spawning in male and female Atlantic salmon (Salmo salar L.). J Fish Biol 39: $739-744$

Kieffer JD (2000) Limits to exhaustive exercise in fish. Comp Biochem Physiol A 126:161-179

Koivula K, Lahti K, Orell M, Rytkönen S (1993) Prior residency as a key determinant of social dominance in the willow tit (Parus montanus). Behav Ecol Sociobiol 33:283-287. https://doi.org/10.1007/ BF02027126

Kokko H, Gunnarsson TG, Morrell LJ, Gill JA (2006) Why do female migratory birds arrive later than males? J Anim Ecol 75:1293-1303. https://doi.org/10.1111/j.1365-2656.2006.01151.x

Kottelat M, Freyhof J (2007) Handbook of European freshwater fishes. Kottelat, Cornol and Freyhof, Berlin

Kř́žek J, Vostradovský J (2002) Population dynamics of the rapacious carp (Aspius aspius L.) in the Želivka reservoir in 1972-1992. In: 4th Int Conf Reserv Limnol water Qual. České Budějovice, Czech Republic, B Abstr, pp 180-182

Kruuk LE, Clutton-Brock TH, Rose KE, Guinness FE (1999) Early determinants of lifetime reproductive success differ between the sexes in red deer. Proc R Soc Lond B 266:1655-1661. https://doi.org/10. 1098/rspb.1999.0828

Limmer B, Becker PH (2009) Improvement in chick provisioning with parental experience in a seabird. Anim Behav 77:1095-1101. https://doi.org/10.1016/j.anbehav.2009.01.015

Limmer B, Becker PH (2010) Improvement of reproductive performance with age and breeding experience depends on recruitment age in a long-lived seabird. Oikos 119:500-507. https://doi.org/10.1111/j. 1600-0706.2009.16673.x

Mark W, Hofer R, Wieser W (1987) Diet spectra and resource partitioning in the larvae and juveniles of three species and six cohorts of cyprinids from a subalpine lake. Oecologia 71:388-396. https://doi.org/10.1007/BF00378712 
McCullagh P, Nelder JA (1989) Generalized Linear Models, 2nd edn. Chapman \& Hall/CRC, Boca Raton, FL

Michelangeli M, Wong BBM, Chapple DG (2016) It's a trap: sampling bias due to animal personality is not always inevitable. Behav Ecol 27:62-67. https://doi.org/10.1093/beheco/arv123

Mittelbach GG, Ballew NG, Kjelvik MK (2014) Fish behavioral types and their ecological consequences. Can J Fish Aquat Sci 71:927944. https://doi.org/10.1139/cjfas-2013-0558

Møller AP (1994) Phenotype-dependent arrival time and its consequences in a migratory bird. Behav Ecol Sociobiol 35:115-122

Møller AP, Balbontín J, Cuervo JJ, Hermosell IG, Lope F (2009) Individual differences in protandry, sexual selection, and fitness. Behav Ecol 20:433-440

Morbey Y (2000) Protandry in Pacific salmon. Can J Fish Aquat Sci 57: 1252-1257. https://doi.org/10.1139/f00-064

Morbey YE (2003) Pair formation, pre-spawning waiting, and protandry in kokanee, Oncorhynchus nerka. Behav Ecol Sociobiol 54:127135. https://doi.org/10.1007/s00265-003-0606-3

Morbey YE, Coppack T, Pulido F (2012) Adaptive hypotheses for protandry in arrival to breeding areas: a review of models and empirical tests. J Ornithol 153:207-215. https://doi.org/10.1007/ s10336-012-0854-y

Morbey YE, Ydenberg RC (2001) Protandrous arrival timing to breeding areas: a review. Ecol Lett 4:663-673. https://doi.org/10.1046/j. 1461-0248.2001.00265.x

Niemelä PT, Lattenkamp EZ, Dingemanse NJ (2015) Personality-related survival and sampling bias in wild cricket nymphs. Behav Ecol 26: 936-946. https://doi.org/10.1093/beheco/arv036

Ojanguren AF, Braña F (2003) Effects of size and morphology on swimming performance in juvenile brown trout (Salmo trutta L.). Ecol Freshw Fish 12:241-246. https://doi.org/10.1046/J.1600-0633. 2003.00016.X

Oliveira RF, McGregor PK, Latruffe C (1998) Know thine enemy: fighting fish gather information from observing conspecific interactions. Proc R Soc Lond B 265:1045-1049. https://doi.org/10.1098/rspb. 1998.0397

Olsson M, Madsen T (1996) Costs of mating with infertile males selects for late emergence in female sand lizards (Lacerta agilis L.). Copeia 1996:462-464

Olsson M, Shine R (2000) Ownership influences the outcome of malemale contests in the scincid lizard, Niveoscincus microlepidotus. Behav Ecol 11:587-590. https://doi.org/10.1093/beheco/11.6.587

Pärt T (2001) Experimental evidence of environmental effects on agespecific reproductive success: the importance of resource quality. Proc R Soc Lond B 268:2267-2271. https://doi.org/10.1098/rspb. 2001.1803

QGIS Development Team (2016) QGIS geographic information system. Open Source Geospatial Foundation Project. https://qgis.org/. Accessed 19 Nov 2019

Quinn TP, Foote CJ (1994) The effects of body size and sexual dimorphism on the reproductive behaviour of sockeye salmon, Oncorhynchus nerka. Anim Behav 48:751-761. https://doi.org/10. 1006/anbe. 1994.1300

R Development Core Team (2020) R: a language and environment for statistical computing. R Foundation for Statistical Computing, Vienna. http://www.R-project.org. Accessed 10 Oct 2020

Rajasilta M (2001) Ovarian weight of the Baltic herring (Clupea harengus membras) in relation to spawning time in the Archipelago Sea, northern Baltic. ICES J Mar Sci 58:106-113

Rebke M, Coulson T, Becker PH, Vaupel JW (2010) Reproductive improvement and senescence in a long-lived bird. P Natl Acad Sci USA 107:7841-7846. https://doi.org/10.1073/pnas.1002645107

Reglero P, Ortega A, Balbín R, Abascal FJ, Medina A, Blanco E, de la Gándara F, Alvarez-Berastegui D, Hidalgo M, Rasmuson L, Alemany F, Fiksen Ø (2018) Atlantic bluefin tuna spawn at suboptimal temperatures for their offspring. Proc R Soc B 285: 20171405. https://doi.org/10.1098/rspb.2017.1405

Robinson MR, Mar KU, Lummaa V (2012) Senescence and age-specific trade-offs between reproduction and survival in female Asian elephants. Ecol Lett 15:260-266. https://doi.org/10.1111/j.1461-0248. 2011.01735.x

Rosenthal MF, Gertler M, Hamilton AD, Prasad S, Andrade MCB (2017) Taxonomic bias in animal behaviour publications. Anim Behav 127: 83-89. https://doi.org/10.1016/j.anbehav.2017.02.017

Ross CT, Jaeggi AV, Borgerhoff Mulder M, Smith JE, Smith EA, Gavrilets S, Hooper PL (2020) The multinomial index: a robust measure of reproductive skew. Proc R Soc B 287:20202025. https://doi.org/10.1098/rspb.2020.2025

Roth TC, Krochmal AR (2015) The role of age-specific learning and experience for turtles navigating a changing landscape. Curr Biol 25:333-337

Scharf I, Peter F, Martin OY (2013) Reproductive trade-offs and direct costs for males in arthropods. Evol Biol 40:169-184

Seamons TR, Quinn TP (2010) Sex-specific patterns of lifetime reproductive success in single and repeat breeding steelhead trout (Oncorhynchus mykiss). Behav Ecol Sociobiol 64:505-513. https://doi.org/10.1007/s00265-009-0866-7

Skov C, Brodersen J, Bronmark C, Hansson L-A, Hertonsson P, Nillson PA (2005) Evaluation of PIT-tagging in cyprinids. J Fish Biol 67: $1195-1201$

Slotte A, Johannessen A, Kjesbu OS (2000) Effects of fish size on spawning time in Norwegian spring-spawning herring. J Fish Biol 56:295-310. https://doi.org/10.1111/j.1095-8649.2000.tb02107.x

Šmejkal M, Blabolil P, Bartoň D, Duras J, Vejǔ́í L, Sajdlová Z, Kočvara L, Kubečka J (2019) Sex-specific probability of PIT-tag retention in a cyprinid fish. Fish Res 219:105325

Šmejkal M, Ricard D, Vejřík L, Mrkvička T, Vebrová L, Baran R, Blabolil P, Sajdlová Z, Vejř́iková I, Prchalová M, Kubečka J (2017) Seasonal and daily protandry in a cyprinid fish. Sci Rep 7: 4737. https://doi.org/10.1038/s41598-017-04827-x

Šmejkal M, Souza AT, Blabolil P, Bartoň D, Sajdlová Z, Vejř́k L, Kubečka J (2018) Nocturnal spawning as a way to avoid egg exposure to diurnal predators. Sci Rep 8:15377. https://doi.org/10.1038/ s41598-018-33615-4

Smith C, Pateman-Jones C, Zieba G, Przybylski M, Reichard M (2009) Sperm depletion as a consequence of increased sperm competition risk in the European bitterling, Rhodeus amarus. Anim Behav 77: 1227-1233. https://doi.org/10.1016/j.anbehav.2009.01.027

Snyder DE (2003) Invited overview: conclusions from a review of electrofishing and its harmful effects on fish. Rev Fish Biol Fish 13:445453

Spinu V, Grolemund G, Wickham H et al (2017) R: Package 'lubridate'. https://CRAN.R-project.org/package=lubridate. Accessed 20 Aug 2019

Stephens PA, Boyd IL, Mcnamara JM, Houston AI (2009) Capital breeding and income breeding: their meaning, measurement, and worth. Ecology 90:2057-2067. https://doi.org/10.1890/08-1369.1

Thériault V, Moyer GR, Jackson LS, Blouin MS, Banks MA (2011) Reduced reproductive success of hatchery coho salmon in the wild: insights into most likely mechanisms. Mol Ecol 20:1860-1869. https://doi.org/10.1111/j.1365-294X.2011.05058.x

Tibblin P, Forsman A, Borger T, Larsson P (2016) Causes and consequences of repeatability, flexibility and individual fine-tuning of migratory timing in pike. J Anim Ecol 85:136-145. https://doi.org/ 10.1111/1365-2656.12439

Trail PW, Adams ES (1989) Active mate choice at cock-of-the-rock leks: tactics of sampling and comparison. Behav Ecol Sociobiol 25:283292. https://doi.org/10.1007/BF00300055

Turner GF (1994) The fighting tactics of male mouthbrooding cichlids: the effects of size and residency. Anim Behav 47:655-662. https:// doi.org/10.1006/anbe.1994.1089 
Ueda H, Yamamoto Y, Hiroshi H (2007) Physiological mechanisms of homing ability in sockeye salmon : from behavior to molecules using a lacustrine model. Am Fish Soc Symp 54:5-16

Vandeperre F, Methven DA (2007) Do bigger fish arrive and spawn at the spawning grounds before smaller fish: cod (Gadus morhua) predation on beach spawning capelin (Mallotus villosus) from coastal Newfoundland. Estuar Coast Shelf Sci 71:391-400

Wickham H (2016) ggplot2 elegant graphics for data analysis. https:// CRAN.R-project.org/package=ggplot 2 . Accessed 15 Oct 2020

Wickham H, Averick M, Bryan J et al (2019a) Welcome to the Tidyverse. J Open Source Softw 4:1686. https://doi.org/10.21105/joss.01686

Wickham H, François R, Henry L, Müller K (2019b) Package 'dplyr' - A Grammar of Data Manipulation. https://CRAN.R-project.org/ package $=$ dplyr. Accessed 15 Oct 2020

Wood SN (2001) mgcv: GAMs and generalized ridge regression for R. R News 1:20-25

Wood SN (2013) On p-values for smooth components of an extended generalized additive model. Biometrika 100:221-228. https://doi. org/10.1093/biomet/ass048
Wood SN (2017) Generalized additive models: an introduction with R, 2nd edn. Chapman \& Hall, Boca Raton

Wooller RD, Bradley JS, Skira IJ, Serventy DL (1990) Reproductive success of short-tailed shearwaters Puffinus tenuirostris in relation to their age and breeding experience. J Anim Ecol 59:161-170. https://doi.org/10.2307/5165

Yang Y, Prémel V, Richards-Zawacki CL (2020) Prior residence effect determines success of male-male territorial competition in a color polymorphic poison frog. Ethology published online, https://doi. org/10.1111/eth.13093

Zhang H, Vedder O, Becker PH, Bouwhuis S (2015) Age-dependent trait variation: the relative contribution of within-individual change, selective appearance and disappearance in a long-lived seabird. J Anim Ecol 84:797-807. https://doi.org/10.1111/1365-2656.12321

Publisher's note Springer Nature remains neutral with regard to jurisdictional claims in published maps and institutional affiliations. 